\title{
Molting and mortality depend on age and stage in naupliar Calanus pacificus: implication for development time of field cohorts
}

\author{
Mai D. G. Lopez \\ Marine Biology Research Division, 0202, Scripps Institution of Oceanography, La Jolla, California 92093, USA
}

\begin{abstract}
Molting success and survivorship increased during naupliar development in the marine calanoid copepod Calanus pacificus studied in the laboratory. However, both rates decreased with age within each instar Simulations of the development of different naupliar stage III (NIII) age-groups suggest that mortality can shorten estimated cohort development times below the minimum possible in individual nauplii. The magnitude of this reduction depends strongly on differences in initial mortality rate among instars. The suggestion that copepod generation times in the field are independent of food availability can be reconciled with the well-established relationship between stage durations and food concentration if a distinction is made between individual and cohort development rates. Individual development rates decrease at low food levels, but with the death of a sufficiently large fraction of slowdeveloping individuals, cohort development rates may remain maximal.
\end{abstract}

\section{INTRODUCTION}

Copepod cohorts develop asynchronously in the field and even under homogeneous and constant laboratory conditions. Thus, individuals of the same age may be in different instars at any given time (Peterson 1986, Carlotti \& Sciandra 1989, Carlotti 1990). The variance in development rate is greatest at naupliar stage III (Peterson 1986), and increases when food is scarce (Sciandra 1986). Because stage durations are extremely time-consuming to observe in individual specimens, one commonly estimates these from the emergence times at successive stages of the median individual in a cohort (e.g. Landry 1983, Peterson \& Painting 1990). Mortality influences such estimates of stage duration through changes in the frequency distribution of individual development rates as the cohort matures. This raises the question of whether differences in apparent stage duration due to shifts in this frequency distribution are of any significance.

In studies of the dynamics of field populations, laboratory-determined stage durations are often used in conjunction with time series of stage-frequency distributions to estimate other population parameters, especially mortality rate (Mullin \& Brooks 1970, Durbin \& Durbin 1981, Omori \& Ikeda 1984, Kimmerer \&
McKinnon 1987). Braner \& Hairston (1989) have shown that mean stage durations in a population should decrease by an amount proportional to their variances and/or the mortality rate. They therefore suggest that stage durations of laboratory-raised cohorts may not apply to field populations in which mortality rates are often much higher. Different stage duration values can result in widely disparate estimates of mortality rate for the same data set, as demonstrated by Landry (1983) in his discussion of the generality of the isochronal rule.

The interaction between mortality and developmental variability may, in theory, also be an important mechanism for population persistence in variable or sub-optimal environments. In insect populations, large variances in development time can damp out fluctuations in egg production so that adult recruitment remains stable (Birley 1979). Mathematical models have been used to evaluate the role of variable development times in stabilizing populations when food is limiting (Agur 1983, Nisbet \& Gurney 1983, Metz et al. 1988), or when the functional response of a predator is destabilizing (Hastings 1983). In equilibrium populations in which birth and development rates are food-dependent, food-limitation may result only in reduced adult recruitment while maturation time remains constant (Frogner 1980). 
It remains to be demonstrated, however, that the mortality rates and developmental variability exhibited by organisms are sufficient to produce the effects predicted by models. In this paper, I examine the degree to which mortality might reduce apparent stage durations in naupliar cohorts of copepods. I present estimates of the age-dependence of stage-specific molting and mortality rates of naupliar stages III to VI (NIII to NVI) of the marine calanoid copepod Calanus pacificus, based on laboratory experiments. The age-dependent functions are applied to hypothetical cohorts differing in initial age (1) to determine the influence of prolonged residence time at NIII on the apparent stage durations of later instars when these are calculated from median emergence times, and (2) to elucidate the mortality patterns required to maintain minimum stage durations. The results are discussed in the context of field conditions

\section{METHODS}

Stock cultures. Mixed zooplankton were caught at approximately monthly intervals in the spring and summer (1988-89), offshore of La Jolla, California, USA $\left(32^{\circ} 50^{\prime} \mathrm{N}, 117^{\circ} 10^{\prime} \mathrm{W}\right)$ with a $0.5 \mathrm{~m}$ diameter, $500 \mu \mathrm{m}$ mesh net. The catch was diluted with surface seawater in plastic coolers and transported to the laboratory within $30 \mathrm{~min}$. Female Calanus pacificus were sorted and maintained in a $4 \mathrm{l}$ plexiglass cylinder with a $300 \mathrm{um}$ mesh bottom, immersed in a pail of Whatman GF/C-filtered seawater (FSW). These were fed abundantly with mixtures of dinoflagellates (Gymnodinium spp., Gyrodinium spp., Prorocentrum minimum) and the diatom Thalassiosira weissflogii. All algae were cultured in Gonyaulax polyedra medium (Loeblich 1975 ) at 20 to $22^{\circ} \mathrm{C}$, in continuous light. The female broodstock was transferred into fresh food suspension at the beginning and end of each egg-collection period.

To obtain a sufficient number of eggs of approximately the same age, females were allowed to spawn for $12 \mathrm{~h}$ periods. The resulting batch of eggs was considered as a cohort, with initial age designated as the mid-point of the collection interval. Eggs were siphoned from the bottom of the broodstock pail into a $102 \mu \mathrm{m}$ mesh sieve and rinsed by repeated dipping in FSW. These were then stocked in glass gallon (3.8 l) jars containing a dense suspension of 5-d-old Prorocentrum minimum (clone PY44, $0.19 \mathrm{ng} \mathrm{C}$ cell $^{-1}$ ) in FSW. This dinoflagellate supports high survival and development rates in Calanus pacificus nauplii (Huntley et al. 1987). At 12 h intervals, ca $50 \mathrm{ml}$ of this medium was removed from each jar by reverse filtration and replaced with fresh $P$. minimum culture. Nauplii at different ages within each stage were raised by starting stock cohorts at different densities (50 to 1000 eggs $l^{-1}$ ). It is assumed that the increase in stage duration at naupliar densities $>200 \mathrm{I}^{-1}$ was due to food limitation. Although abundant food was supplied, cell concentrations could not be closely monitored and it is likely that these intermittently fell below that required to support maximum development rate. Broodstock and nauplii were kept at $14.5( \pm 1.0)^{\circ} \mathrm{C}$ in continuous dim light.

Determination of age-dependent molting and mortality rates. To quantify molting and mortality rates, nauplii from stock cohorts of a known age were sorted according to stage under a dissecting microscope. Groups of 50 (NIV to NVI) or 70 (NIII) nauplii were placed in $300 \mathrm{ml}$ crystallizing dishes containing $200 \mathrm{ml}$ of Prorocentrum minimum suspension at $800 \mu \mathrm{g} \mathrm{Cl}^{-1}$ In these experiments, food was replenished every $12 \mathrm{~h}$, after removal of an equivalent amount of the medium (ca $20 \mathrm{ml}$ ) which was used to determine cell concentrations by visual enumeration in settled volumes using the Utermöhl method (Lund et al. 1958). Food concentrations never fell below $400 \mu \mathrm{g} \mathrm{C} \mathrm{l}^{-1}$. After $3 \mathrm{~d}$ of incubation, each group was examined under a dissecting microscope to evaluate survivorship and stage distribution.

The above protocol was adopted after preliminary experiments had shown that daily transfers of nauplii into fresh food suspension resulted in high mortality. Aeration was not attempted because it damages nauplij (Thompson 1982). When small aliquots of the medium were replaced twice daily with fresh food suspension, cohorts could be raised from eggs to $\mathrm{CI}$ in $10 \mathrm{~d}$ with survivorship ranging from 78 to $94 \%$. Differences in survivorship could only be attributed to variation in the 'quality' of cohorts because rearing conditions were constant (Lopez unpubl.). Other workers have successfully used similar stocking densities and/ or smaller container volumes to culture crustacean larvae (e.g. Vidal 1980a, Anger et al. 1981, Lonsdale 1981, Thompson 1982, Dawirs 1984)

Data for naupliar stages NIII to NVI were generated in a total of 87 experiments. For each experiment, the average daily mortality coefficient $(m)$ was calculated assuming that the mortality rate was exponential. Thus:

$$
m=-\left[\ln \left(N_{\ell} / N_{0}\right) / d\right]
$$

where $N_{t}=$ number of nauplii surviving; $N_{0}=$ initial number of nauplii; and $d=$ incubation time in days. Molting rate (\% molt) was based on the number of surviving nauplii which had advanced into all later stages over the $3 \mathrm{~d}$ incubation period, relative to the total number of survivors:

$$
\% \text { molt }=100\left[\left(N_{t}-N_{i}\right) / N_{t}\right]
$$


where $N_{s}=$ number of surviving nauplii remaining at the initial stage. For statistical analyses, molting percentages were arcsine-transformed to normalize their distributions. Naupliar age was estimated as the time elapsed since the mid-point of the egg-collection interval. The relationships of mortality coefficients and molting percentages to naupliar age and stage were determined by regression analysis (Sokal \& Rohlf 1981, Wilkinson 1989).

\section{RESULTS}

\section{Age-dependent molting and mortality rates}

Within each stage, the percentage of nauplii which molted after $3 \mathrm{~d}$ of incubation decreased with age (Fig. 1). The rate of decrease was not detectably different among stages $(\mathrm{p}=0.364$ ) although the initial molting rate was lower for NIII than for the subsequent stages $(p<0.001)$. Age accounted for 15 to $53 \%$ of the variance in molting rates within each stage, as follows:

NIII: $A \sin (\%)=66.9-2.5 d\left(r^{2}=0.189, p=0.030\right)$

NIV: $A \sin (\%)=71.6-2.2 d\left(r^{2}=0.150, n s\right)$

$\mathrm{NV}: \quad A \sin (\%)=108.5-3.7 d\left(\mathrm{r}^{2}=0.529, \mathrm{p}<0.001\right)$

NVI: $A \sin (\%)=88.9-1.7 d\left(\mathrm{r}^{2}=0.218, \mathrm{p}=0.011\right)$

where $A \sin (\%)=$ arcsine-transformed molting percentage, and $d=$ age in days.
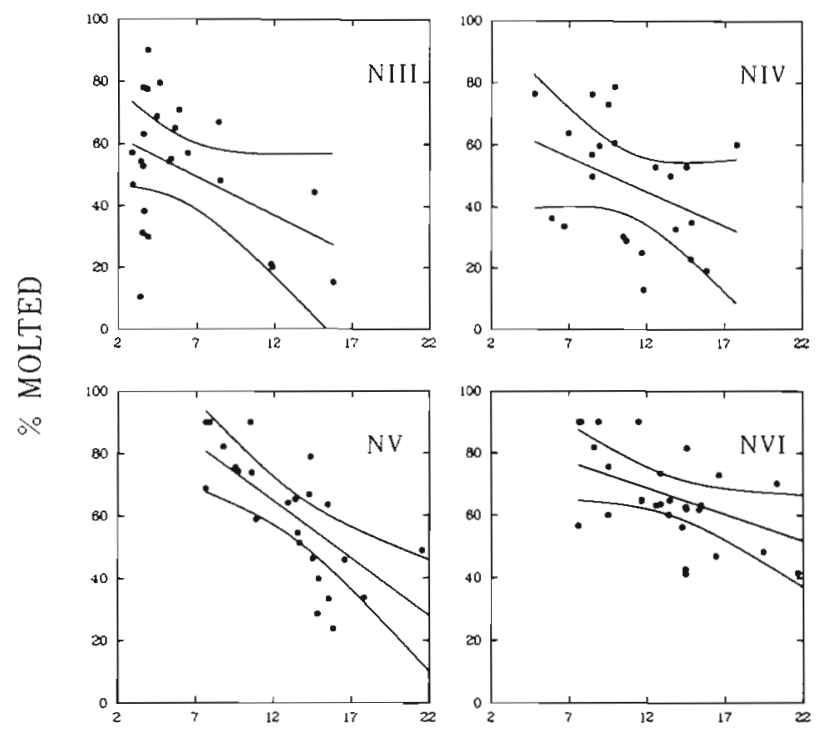

$\mathrm{AGE}(\mathrm{D})$

Fig. 1. Calanus pacificus. Molting percentage of nauplii (NIV-NVI) at different ages within each stage. Data points are arcsine-transformed percentages. Regression lines and $95 \%$ confidence intervals are shown
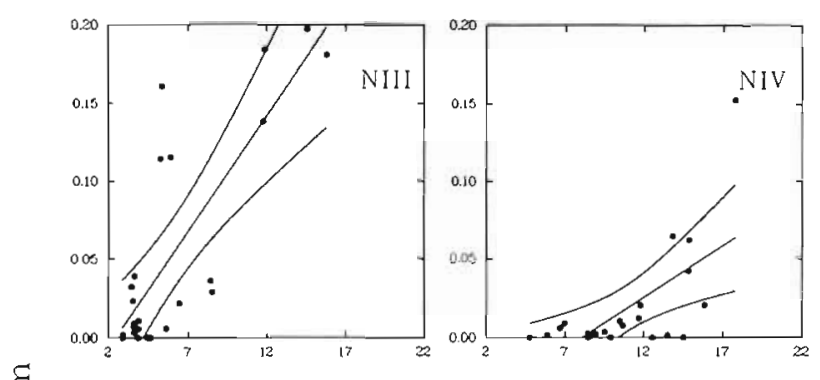

$\Xi$
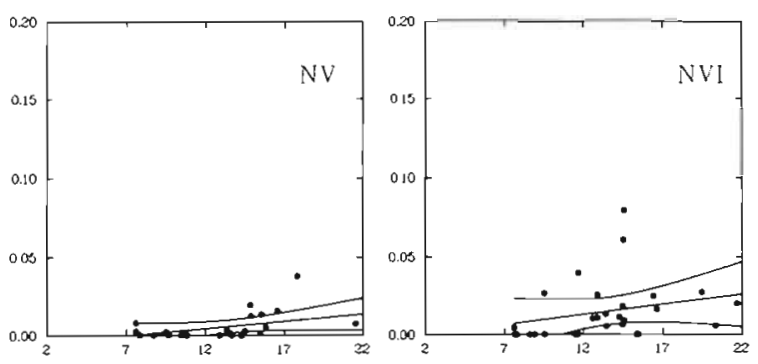

$\operatorname{AGE}(D)$

Fig. 2. Calanus pacificus. Mortality coefficients $\left(d^{-1}\right)$ of nauplii (NIV-NVI) at different ages within each stage. Regression lines and $95 \%$ confidence intervals are shown

The daily mortality coefficient $(m)$ increased with age for NIII to NV, but not for NVI (Fig. 2). The agedependent rate of increase in $m$ decelerated from stages NIII to NV. Age explained 18 to $65 \%$ of the variance of $m$ within a stage, as follows:

NIII $m=-0.035+0.015 d \quad\left(\mathrm{r}^{2}=0.646, \mathrm{p}<0.001\right)$

NIV $: m=-0.053+0.007 d \quad\left(\mathrm{r}^{2}=0.418, \mathrm{p}=0.001\right)$

NV: $m=-0.007+0.001 d \quad\left(\mathrm{r}^{2}=0.180, \mathrm{p}=0.03\right)$

NVI: $m=-0.003+0.001 d \quad\left(\mathrm{r}^{2}=0.078, \mathrm{~ns}\right)$

where $m=$ daily mortality coefficient $\left(d^{-1}\right)$. Although the regressions of stage-specific molting percentage and daily mortality on age were significant (with the exception of molting in NIV, and NVI mortality), the coefficients of determination indicate that age alone explained a relatively small fraction of the variability in both.

Molting percentage and mortality rates were compared across stages by pooling data for each rate in a step-wise multiple regression analysis (Wilkinson 1989). Development into later instars was associated with an increase in the molting percentage and a decrease in the daily mortality coefficient, such that:

$$
\begin{gathered}
A \sin (\%)=31.6+5.50 n \quad\left(\mathrm{r}^{2}=0.100, \mathrm{p}=0.001\right) \\
m=0.056-0.013 n \quad\left(\mathrm{r}^{2}=0.115, \mathrm{p}=0.001\right)
\end{gathered}
$$

where $n=3,4,5$ and 6 for NIII, NIV, NV and NVI, respectively. Adding age as an independent variable 
increased the explained variance in both molting percentage and $m$ :

$$
\begin{aligned}
& A \sin (\%)=31.0+11.6 n-2.5 d\left(\mathrm{r}^{2}=0.337, \mathrm{p}<0.001\right)(11) \\
& m=0.036-0.022 n+0.004 d\left(\mathrm{r}^{2}=0.248, \mathrm{p}<0.001\right)
\end{aligned}
$$

The standardized coefficients for both equations show that age and stage are similarly important in determining molting percentage $(-0.602$ and 0.669 , respectively), but stage accounts for more of the variance in the mortality rate than does age $(-0.598$ vs 0.448$)$.

\section{Sinulations}

To determine if naupliar stage durations could be significantly reduced by the interaction between agedependent molting and mortality, I used Eqs. (1) to (8) to simulate the development and survival to copepodite I of different age groups of stage III nauplii. Because the equations for molting percentage are based on results after $3 \mathrm{~d}$ of incubation, molting in the simulated age groups was constrained to begin only after $3 \mathrm{~d}$ within each stage. In these artificial cohorts, therefore, the minimum duration of all stages is $3 d$, with the distribution of longer residence times being set by Eqs. (1) to (4). Stage durations of Calanus pacificus NIII to NVI, calculated from median emergence times in Landry (1983), are $2 \mathrm{~d}$ or less. Thus, the $3 \mathrm{~d}$ minimum stage duration used in these simulations overestimates age-dependent mortality by retaining an unknown fraction of survivors within the same stage for longer than expected, and by delaying the emergence times of all more advanced stages. Initial values of $m$, from Eqs. (4) to (8), increased with advancing stage as follows: NIII: 0 at age $=2 \mathrm{~d}$; NIV: 0 at age $=5 \mathrm{~d}$; NV: 0.001 at

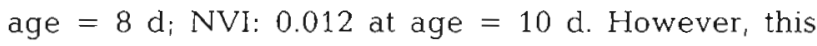
affects neither the relative magnitudes of molting and mortality patterns among age groups nor the general conclusions.

Fig. 3 shows the survival curves of NIII cohorts aged $2,4,6,8$, and $10 \mathrm{~d}$ as these develop into the first copepodite stage, CI. Survival to CI exceeded $90 \%$ among 2 -d-old NIII and was ca $40 \%$ among 10 -d-old NIII. The proportion of nauplii surviving to $\mathrm{CI}$ decreased linearly with the age attained as NIII:

$$
\operatorname{Arcsin}(p)=80.3-4.1 d \quad\left(r^{2}=0.997\right)
$$

where $p=$ the proportion of the age group surviving to $\mathrm{CI}$; and $d=$ age at NIII. The average mortality coefficient for the period from NIII to CI was $0.0061 \mathrm{~d}^{-1}$ for the Day 2 age group, and $0.045 \mathrm{~d}^{-1}$ for the Day 10 age group.

Stage durations of NIV to NVI for each age group were calculated from median emergence times and are plotted against age at NIII in Fig. 4. Differences in stage

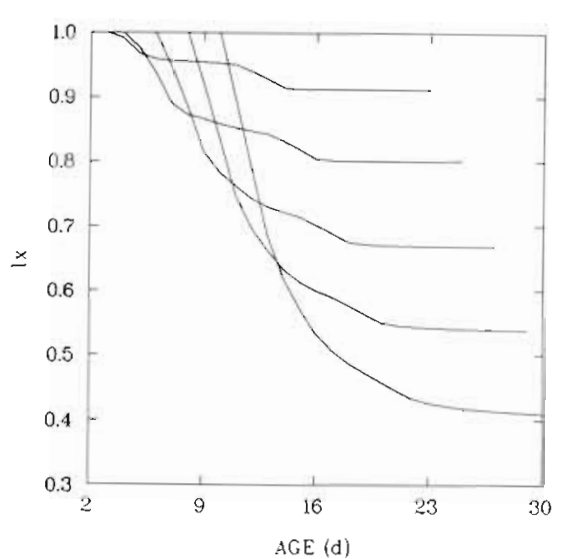

Fig. 3. Simulations. Survivorship $\left(I_{x}\right)$ of age groups of stage III nauplii through complete development to copepodite stage I (CI). Curves were generated using age-dependent molting percentages and mortality coefficients predicted from Eqs. (1) to (8) (see text)

duration, expressed as percentages of the durations calculated for the Day 2 age group, are plotted against survivorship at the corresponding median emergence time in the different age groups in Fig. 5. The 7-fold difference in average mortality rate between the Day 2
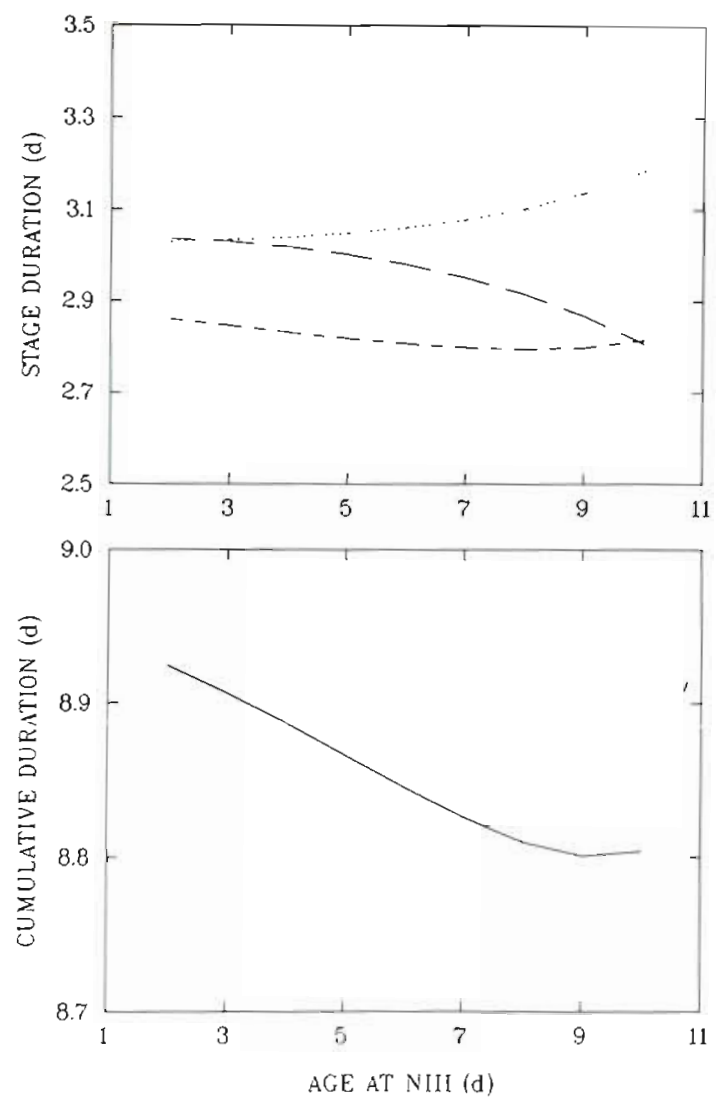

Fig. 4. Simulations. Effect of age-dependent mortality on stage durations of naupliı. developing from different NIII age groups. Minimum duration of each stage is $3 \mathrm{~d}$. (....) NIV; $(-\ldots)$ NV; (-- - NVI; (-) NIV to NVI 


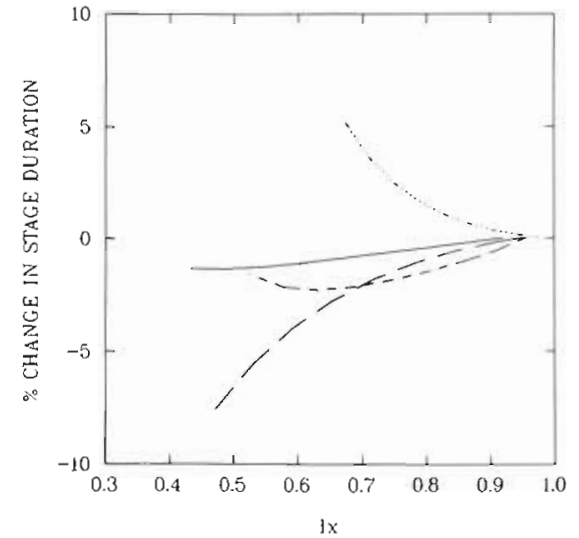

Fig. 5. Simulations. Changes in stage durations of nauplii developing from different NIII age groups, as functions of cohort survivorship at median emergence time at respective stages. Percentages are calculated relative to stage durations in the youngest (Day 2) age group. (...) NIV; (-..) NV; $(-\longrightarrow)$ NVI; (一) NIV to NVI

and Day 10 age groups reduced the apparent durations of NV and NVI by ca 2 and $8 \%$, respectively. However, a concomitant increase in NIV stage duration resulted in the cumulative residence time from NIV to NVI decreasing by only $1 \%$. This simulation suggests that mortality rates due to ageing within NIII alone are insufficient to produce a significant reduction in the total estimated naupliar duration of survivors. On the other hand, the cumulative residence time in subsequent naupliar instars can approximate that expected when development rates are maximal.

I then determined whether the results would be any different if the higher mortality rates estimated for field populations were used. Mullin \& Brooks (1970) calculated mortality coefficients for Calanus pacificus nauplii as a group, based on field data from La Jolla Bay, while Fager (1973) supplied probable ranges for stagespecific mortality coefficients using the same data set. I used these published values to determine the effects of the following mortality patterns:

Case 1: Equal mortality coefficients for all stages [as assumed by Mullin \& Brooks (1970)] at the earliest age within each stage. The following values were used in separate simulations: $0.33,0.65$ and 1.51 .

Case 2: Decreasing initial mortality coefficients with advancing stage, using the lower (a) and upper (b) limits of stage-specific ranges given by Fager (1973):
(a) NIII: $1.51, \mathrm{NIV}: 0.78, \mathrm{NV}: 0.10, \mathrm{NVI}: 0.05$.
(b) NIII: 3.14, NIV: 1.51, NV: 0.78, NVI: 0.10 .

In applying these rates, I assumed that for nauplii which survived without molting into the next stage, the rate at which $m$ changed with age remained as in Eqs. (5) to (8). This implies that the additional cause of mortality, presumably predation, acts uniformly on all individuals within a stage. Thus, only the intercept of each stage-specific regression equation was changed to give the specified initial value of $m$. I further assumed that for nauplii which survived without molting, the decrease in the molting percentage with age remained as given in Eqs. (1) to (4).

Fig. 6 shows the durations of stages NIV to NVI which develop from different NIII age groups when these are subject to the mortality rates specified for Cases 1 and 2. When the mortality coefficient was allowed to be equal for all stages at the earliest age (Case 1), the general pattern of changes in stage duration among age groups remained essentially the same as in the first simulation where initial mortality rates increased with advancing stage. More importantly, stage durations within an age group were the same regardless of the magnitude of the initial mortality rate. The average mortality rate from NIII to CI ranged from 0.37 to $1.59 \mathrm{~d}^{-1}$ (Table 1). Cumulative time spent at NIV to NVI was up to $2 \%$ shorter than the hypothetical minimum.

When the initial mortality rate was allowed to decrease in more advanced stages (Case 2), results were quite different. The durations of all remaining naupliar stages decreased continuously among older age groups, with the percentage reduction increasing
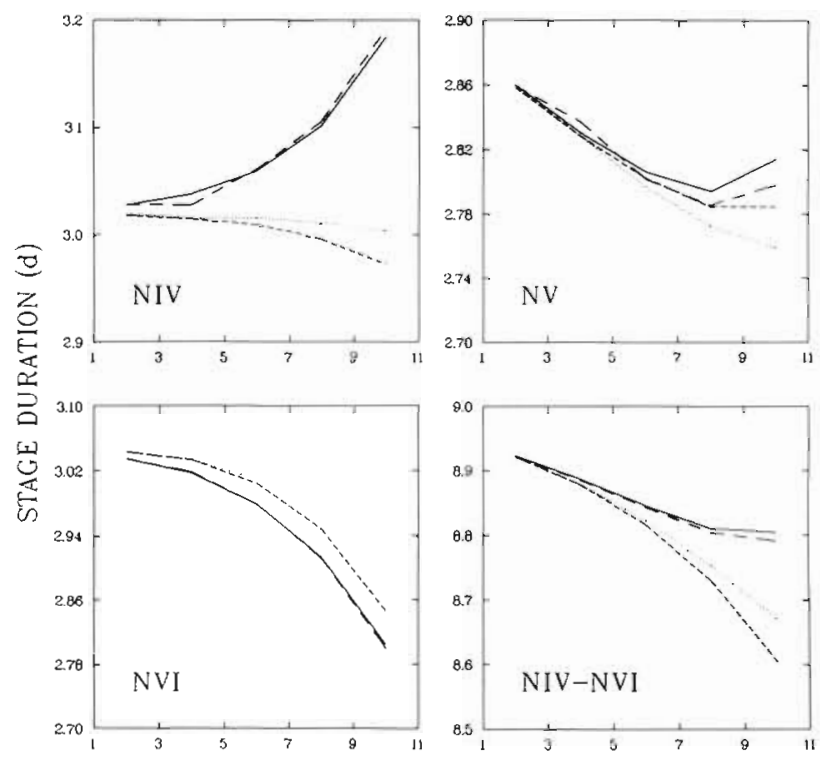

Fig. 6. Simulations. Effect of different mortality patterns on stage durations of nauplii developing from different NIII age groups. (-) $m=$ age-dependent rates from Eqs. (5) to (8); (- - $m=0.33,0.65$ and $1.51 \mathrm{~d}^{-1}$, assuming that the initial value is equal for all stages at the earliest emergence time. $(\cdots) m=$. lower limit of stage-specific mortality rates given by Fager (1973), applied at the earliest emergence time of each stage. (-.-) $m=$ upper limit of stage-specific mortality rates given by Fager (1973), applied at the earliest emergence time of each stage 
in the more advanced instars. With this mortality pattern, cumulative time from NIV to NVI in the Day 10 age group was 3 to $4 \%$ lower than that in the Day 2 age group, and up to $4.4 \%$ lower than the hypothetical minimum of $9 \mathrm{~d}$. The average mortality rate for the period from NIII to $\mathrm{Cl}$ ranged from 0.64 to $1.57 \mathrm{~d}^{-1}$ (Table 1).

\section{DISCUSSION}

\section{Stage-specific molting and mortality rates}

The experimental results show that individuals with slow development rates, i.e. those which remain longer within each stage, have poorer chances of surviving and advancing to the next stage [Eqs. (1) to (8)]. While such nauplii may eventually molt, they remain at a disadvantage by entering the subsequent stage at a later age. Thus, the early development rates of individuals can influence their development rates in later stages. This further suggests that there is a continuous culling of laggards during ontogeny, so that only the fastest developing individuals survive. Hence, both molting percentage and survivorship improve in the later stages [Eqs. (9) to (12)]. The selection apparently begins at NIII and is sufficiently rapid that nauplii which survive to NVI experience no age-dependent increase in mortality rate, and a negligible decrease in molting percentage, at least within the age range covered.

This is consistent with the observation that the variance in development rate is highest at NIII for Calanus

Table 1. Calanus pacificus. Effects of different mortality patterns on the average daily mortality rate and survivorship $\left(I_{x}\right)$ to copepodite I of simulated Day 2 and Day 10 NIII age groups

\begin{tabular}{|c|c|c|c|}
\hline $\begin{array}{l}\text { Initial } m \\
\left(d^{-1}\right)\end{array}$ & $\begin{array}{l}\text { NIII } \\
\text { Age group }\end{array}$ & $\begin{array}{l}\text { Mean } m \\
\text { (NIII-CI) }\end{array}$ & $\begin{array}{l}\text { Survivorship } \\
\qquad\left(l_{x}\right)\end{array}$ \\
\hline \multicolumn{4}{|c|}{ a. Initial mortality rate equal for all stages: } \\
\hline 0.33 & $\begin{array}{r}2 \\
10\end{array}$ & $\begin{array}{l}0.37 \\
0.41\end{array}$ & $\begin{array}{l}1.74 \times 10^{-2} \\
7.71 \times 10^{-3}\end{array}$ \\
\hline 0.65 & $\begin{array}{r}2 \\
10\end{array}$ & $\begin{array}{l}0.66 \\
0.73\end{array}$ & $\begin{array}{l}3.74 \times 10^{-4} \\
1.66 \times 10^{-4}\end{array}$ \\
\hline 1.51 & $\begin{array}{r}2 \\
10\end{array}$ & $\begin{array}{l}1.52 \\
1.59\end{array}$ & $\begin{array}{l}1.23 \times 10^{-8} \\
5.46 \times 10^{-9}\end{array}$ \\
\hline \multicolumn{4}{|c|}{ b. Initial mortality rate decreasing in later stages: } \\
\hline $\begin{array}{l}\text { NIII: } 1.51 \\
\text { NIV: } 0.78 \\
\text { NV } 0.10 \\
\text { NVI: } 0.05\end{array}$ & $\begin{array}{r}2 \\
10\end{array}$ & $\begin{array}{l}0.64 \\
0.76\end{array}$ & $\begin{array}{l}4.56 \times 10^{-4} \\
1.15 \times 10^{-4}\end{array}$ \\
\hline $\begin{array}{l}\text { NIII: } 3.14 \\
\text { NIV } 1.51 \\
\text { NV } 0.78 \\
\text { NVI: } 0.10\end{array}$ & $\begin{array}{r}2 \\
10\end{array}$ & $\begin{array}{l}1.55 \\
1.57\end{array}$ & $\begin{array}{l}3.94 \times 10^{-8} \\
6.91 \times 10^{-9}\end{array}$ \\
\hline
\end{tabular}

marshallae, C. australis and Calanoides carinatus, and decreases in later stages (Peterson 1986, Peterson \& Painting 1990). Peterson (1986) observed in C. marshallae that clutches which developed faster in earlier stages did not necessarily continue to do so in later stages. However, it is not clear how much his estimates of median development time may have been influenced by intra-clutch mortality rates (see next section). In individually observed Temora stylifera and Centropages typicus, faster developing copepodites consistently exhibit lower per capita mortality rates. While some fast developers slowed down in later stages, an increase in development rate was never observed in slow individuals (Carlotti 1990). Thus, it appears that the culling process continues during the copepodite stages into adulthood.

These results imply that as a cohort ages, its average development rate increases. This is analogous to what is referred to in fish populations as 'Lee's phenomenon', in which the selective mortality of some size classes results in an apparent difference in early growth rates among year classes (Lee 1912). Faster growing individuals in a year-class recruit earlier into the fishery, so that as it ages, the year class includes an increasingly larger proportion of slow-growing individuals. Jones (1958) showed that if mortality rate is linearly related to length, the difference between the observed and expected mean length of a year class should be equal to the product of the mortality rate and the variance in lengths. For populations in which developmental stages can be distinguished, Braner \& Hairston (1989) independently showed that mean stage duration decreases in the presence of mortality, with the decrease being equal to the product of the mortality rate and the variance in stage duration.

Age explained a relatively small percentage of the variance in stage-specific molting percentages and mortality coefficients. Other factors influence these rates in copepods and other crustaceans. Natural populations of copepods exhibit considerable genetic variation (McLaren \& Corkett 1978, Marcus 1985), and a number of vital rates, including development, have been shown to be heritable (McLaren 1976a, b). In Calanus marshallae, maturation time under the same conditions can differ by up to $18 \mathrm{~d}$ among different clutches (Peterson 1986: his Table 2). Maternal condition may also contribute to variability in the physiological rates of naupliar cohorts. Survivorship decreases in successive clutches from the same female in the copepod Scottolana canadensis (Lonsdale 1981). In the cladoceran Daphnia magna, larval fat content and survivorship are related to maternal fat content and diet (Tessier et al. 1983, Cowgill et al. 1984). Thus, it is not surprising that age and stage alone are weak predictors of naupliar performance. 
In the present experiments, prolongation of stage durations in stock cohorts was presumably due to intermittent food limitation. Nauplii were given relatively abundant food during the subsequent $3 \mathrm{~d}$ incubation period. It is not clear if molting and mortality rates would have been significantly different if lower food concentrations had been provided. In decapods, molting can proceed independently of food availability when larvae reach the transition point between the intermolt and premolt stages of the molting cycle (the ' $D_{0}$ threshold': Anger 1987). However, molting occurs only after some fixed proportion of the premolt biomass as well as a threshold hormonal titer have been accumulated (Anger \& Dawirs 1981, Skinner et al. 1985, Anger \& Spindler 1987). Thus, the approach to this threshold, if it occurs in copepods, must depend on food concentrations. The simultaneous decrease in survivorship and molting percentage with age in each stage implies that $3 \mathrm{~d}$ with abundant food cannot compensate for previous food limitation in older nauplii.

\section{Influence of mortality rate on apparent stage durations}

The median emergence time of a cohort at each stage is the time at which $50 \%$ of the cohort has entered or passed that stage. This is estimated by interpolation from the cumulative percent distribution over time. The duration of stage $i$ is estimated from the difference between median emergence times at stage $i$ and stage $(i+1)$ (Landry 1983). In the initial simulation, mortality-induced reductions in stage duration occurred after NIV. This suggests that development rates, even within the Day 10 age group, were sufficiently fast that the effects of mortality due to physiological ageing became manifest only after at least 2 molts had occurred. By itself, age-dependent mortality due to food limitation cannot significantly reduce the total time spent in stages NIV to NVI. While the reductions are minor, however, the simulation demonstrates that the apparent stage duration measured on the basis of stage frequencies can actually be lower than the minimum possible for individuals in these hypothetical cohorts. This happens because the median position at 2 different time points will not be occupied by the same individual when there are deaths in the intervening period. If slow developers are selectively culled, the difference in median emergence times at stage $i$ and stage $(i+1)$ is the interval between the late arrival of an individual at stage $i$ and the early arrival of a different individual at stage $(i+1)$.

In Calanus pacificus cohorts, a percentage decrease in apparent stage durations larger than that obtained in the Case 2 simulations can occur at much lower mortal- ity rates, as shown in Table 2 (Lopez unpubl.). In this experiment, the treatment cohort was fed at age $2.3 \mathrm{~d}$, when it consisted almost exclusively of stage III nauplii, while the control cohort was fed at age $0 \mathrm{~d}$ (as eggs). Calculated median emergence time at NIII was on Day 2.4 in the late-fed cohort, and on Day 2.0 in the control cohort. Mortality in the late-fed cohort was higher than in the control from Day 4, and increased progressively through Day 10. At the end of the experiment, survivorship averaged $93 \%$ in the control (mean $m=0.007 \mathrm{~d}^{-1}$ ) and $44 \%$ in the late-fed cohort (mean $m=0.047 \mathrm{~d}^{-1}$ ). Stage durations of late-fed nauplii were longer than those of controls at NII and NIII, but decreased continuously until an apparent duration of $0.9 \mathrm{~d}$ was attained at NVI, $18 \%$ lower than among controls. For further comparison, Landry (1983) calculated the stage duration of NVI C. pacificus to be $30.6 \mathrm{~h}, 16$ and $42 \%$ longer than those calculated for the control and late-fed cohorts in Table 2 , respectively.

To facilitate the comparison of development rate estimates for different copepod species, Peterson \& Painting (1990) have recommended that 'median development time' calculated as above should be the method of choice. As they have pointed out, this method does not involve the implicit assumption that development is isochronal. However, the present simulations suggest that biased estimates of median development time may still arise from differences in mortality rate. This magnitude of this bias can be evaluated if estimates of mortality are provided with the corresponding median development time. Demonstrating that mortality in culture was not confined to slow-developing individuals would improve the reliability of the stage duration estimate.

The relative magnitudes of initial stage-specific mortality rates strongly influence the degree to which stage durations can be reduced. Reductions in cumulative time from NIV to CI were greater when it was assumed that initial mortality rates decreased with advancing stage (Case 2), compared to results with the assumption that all stages had the same rates at earliest emergence

Table 2. Calanus pacificus. Effects of mortality on stage durations calculated from median emergence times. Control cohort was fed from Day 0 (as eggs); treatment cohort was fed starting from Day 2.3 (as NIII). Median emergence time is age in days; stage duration is in days

\begin{tabular}{|lcccc|}
\hline Stage & \multicolumn{2}{c}{$\begin{array}{c}\text { Median emergence time } \\
\text { Control }\end{array}$} & $\begin{array}{c}\text { Treatment } \\
\text { Control }\end{array}$ & $\begin{array}{c}\text { Treatment } \\
\text { Contion }\end{array}$ \\
\hline NIII & 2.0 & 2.4 & 2.3 & 3.9 \\
NIV & 4.3 & 6.3 & 2.2 & 2.0 \\
NV & 6.5 & 8.3 & 1.2 & 1.0 \\
NVI & 7.7 & 9.3 & 1.1 & 0.9 \\
CI & 8.8 & 10.2 & & \\
\hline
\end{tabular}


(Case 1). This was true even when the average mortality rate from NIII to $\mathrm{CI}$ was higher in the constant mortality case (i.e. Day 10 groups, Case 1 vs Case 2a; Table 1). The analysis of Braner \& Hairston (1989) implies that the average residence time in the naupliar stages may decrease, even under conditions known to retard development rates in the laboratory, if mortality and/or the variance in residence times are sufficiently high. My simulations show that when development rates are as fast as for Calanus pacificus nauplii, this is more likely if initial stage-specific mortality rates are higher in the earlier stages. In a real cohort, where fast and slow developers are mixed, reductions in apparent stage duration can be much greater than predicted by the simulations (Table 2).

Mortality patterns observed in naupliar cohorts in the field include both constant and decreasing rates with advancement in stage (e.g. Fager 1973, Gehrs \& Robertson 1975, Durbin \& Durbin 1981, Uye 1982). Field rates are also much higher than can be accounted for by ageing alone. Although these have occasionally been inferred to have been caused by starvation (e.g. Weglenska 1971, Rigler \& Cooley 1974, Myers \& Runge 1983, Kimmerer \& McKinnon 1987), high field mortality rates must ultimately be due to predation (Confer \& Cooley 1977, Landry 1978, Ohman 1986). Size, mobility, and detectability by predators are critical factors which determine the vulnerability of zooplankton to predation (Brooks \& Dodson 1965, Zaret 1972, Arthur 1976, Greene 1988). All these factors increase from NI to NVI in Calanus pacificus (Greene 1986). The species composition of a predator assemblage should also be important in determining the relative magnitudes of predation mortality among the developmental stages of C. pacificus. The food spectrum of larval fish, probably the major predator of copepod nauplii in most systems, tends to broaden toward larger size classes as larvae increase in length (Arthur 1976, Hunter 1981). The vulnerability of $C$. pacificus to conspecifics and to the copepods Tortanus discaudatus, Labidocera trispinosa. Euchaeta elongata and Neocalanus cristatus increases from NII to NVI, and declines in the copepodite stages (Greene 1988). On the other hand, the prey-size preferences of Acartia tonsa (Lonsdale et al. 1979) suggest that this genus may feed only on the earliest stages of $C$. pacificus, if at all. Predation by the chaetognath Sagitta elegans on C. pacificus developmental stages follows the same pattern as that exhibited by larger copepods, while the ctenophore Pleurobrachia bachei has increasingly higher feeding rates on more advanced stages through CV (Greene 1986). Vertical profiles of various zooplankton taxa provided by Mullin et al. (1985) show that the distribution of potential predators of C. pacificus nauplii varies widely with time of day and weather conditions. Despite the broad range of possible predation rates that this implies, the present simulations suggest that field mortality rates may be sufficient to maintain maximum cohort development rates.

There is a paucity of published data from which the variance of stage durations of copepods can be quantified, although Sciandra (1986) has observed that the variance increases at low food levels. Instar durations of Eodiaptomus japonicus have higher coefficients of variation at natural and low food concentrations than in enriched water (Kawabata 1989). Thus, feeding conditions which increase individual stage durations simultaneously increase the variance in development rate, which in turn should contribute to stabilizing average stage durations.

\section{Does the generation time of copepods depend on food availability?}

McLaren (1978) has suggested that the generation times of temperate marine copepods are uninfluenced by food supply and are determined by temperature alone. On the other hand, the abundant evidence for food-limited development rates in the laboratory is irrefutable (e.g. Paffenhöfer 1970, Vidal 1980b, Klein Breteler et al. 1982, Huntley et al. 1987, Berggreen et al. 1988). The food vs temperature question is difficult to resolve using field data for several reasons:

(1) Identification of cohorts is often ambiguous because pulses in the abundance of successive stages may be spread over long periods or may not occur at all (Mullin \& Brooks 1967, Durbin \& Durbin 1981, Uye 1982). This results from protracted spawning intervals, which are expected when food is abundant. Even if spawning pulses are distinct and well-spaced, there may be significant differences in maturation time even among individuals from the same clutch raised in abundant food (e.g. Peterson 1986). Finally, the question remains as to whether or not co-occurring individuals within a sample (or worse, in a time-series) do represent a single population.

(2) While food concentrations for particle feeders in the ocean are generally considered to be low, it is not clear how well the quantities measured (e.g. carbon, chlorophyll) correspond to the food spectrum utilized by zooplankton. In addition, the food supply is often estimated from large, well-mixed point samples which do not adequately reflect the in situ microscale aggregations to which copepods are actually exposed. On the other hand, although small, high-density particle patches occur in the ocean (Derenbach et al. 1979, Owen 1989), it remains to be demonstrated that copepods are able to find and remain in them long enough to profit from their existence. 
(3) If patchiness of food distributions is such that individuals comprising a field sample have extremely varied feeding histories (Båmstedt 1988), how is the feeding history of a cohort to be defined? Will 'cohort feeding history' then be a good predictor of generation time?

Braner \& Hairston (1989) suggest that extrapolation of laboratory-measured development rates to field situations where mortality is at least one order of magnitude higher may be misleading. The simulations and empirical observations in this paper show that stage durations calculated from stage frequencies can be shorter than the minimum possible, and thus may not reflect the actual stage durations of any individual within the population. The suggestion by McLaren (1978) can be reconciled with laboratory results if a distinction is made between individual and cohort development rates: food limitation does prolong individual development, but if the ensuing increase in mortality decimates a sufficiently large fraction of slow developers, the apparent development rate of the cohort may remain maximal. In a simulation of larval fish survival incorporating food-limited growth, Jones \& Henderson (1988) have also concluded that predators may eliminate slow-growing larvae before these show any signs of resource limitation.

This hypothesis is testable in populations where cohorts can be reliably identified. Individual development times can be estimated by incubation techniques (e.g. Landry 1978, Kimmerer 1983, Miller er al. 1984, Kawabata 1989), and compared with development times estimated from stage frequencies in field samples (e.g. Aksnes \& Hoisæter 1987, Hairson et al. 1987. Saunders \& Lewis 1987). Differences between the 2 estimates can be used to calculate a mortality rate which may be largely attributable to predator species in the field samples.

Acknowledgements. This work was supported by NSF Grant No. OCE 89-00497 to M. E. Huntley. Scholarship support was provided by UNDP Project No. PHI/84/002/A/01/99. I extend my gratitude to M. E. Huntley, N. D. Holland, M. M. Mullin, P. F. Sykes, F. Escritor and J. Lovette, all of whom have generously helped in various ways; and to 2 anonymous reviewers for their constructive comments.

\section{LITERATURE CITED}

Agur, Z. (1983). Persistence in uncertain environments. In: Freedman, H. I., Strobeck, C. (eds.) Population biology. Springer-Verlag, Berlin, p. 125-132

Aksnes, D. L., Hoisæter, T. J. (1987). Obtaining life table data from stage-frequency distributional statistics. Limnol. Oceanogr. 32: 514-517

Anger, K. (1987). The $D_{0}$ threshold: a critical point in the larval development of decapod crustaceans. J. exp. mar. Biol. Ecol. 108: 15-30
Anger, K. Dawirs, R. R. (1981). Influence of starvation on the larval development of Hyas araneus larvae (Decapoda, Majidae). Helgoländer Meeresunters. 34: 287-311

Anger, K., Spindler, K.-D. (1987). Energetics, moult cycle, and ecdysteroid titers in spider crab (Hyas araneus) larvae starved after the $D_{0}$ threshold. Mar. Biol. 94: 367-375

Anger, K., Dawirs, R. R., Anger, V., Costlow, J. D. (1981). Effects of early starvation periods on zoeal development of brachyuran crabs. Biol. Bull. mar. biol. Lab., Woods Hole 161: 199-212

Arthur, D. K. (1976). Food and feeding of larvae of three fishes occurring in the California Current, Sardinops sagax, Engraulis mordax, and Trachurus symmetricus. Fish. Bull. U.S. $74: 517-530$

Båmstedt, U. (1988). Ecological significance of individual variability in copepod bioenergetics. Hydrobiologia 167/168: $43-59$

Berggreen, V., Hansen, B., Kiørboe, T. (1988). Food size spectra, ingestion and growth of the copepod Acartia tonsa during development: implication for determination of copepod production. Mar. Biol. 99: 341-352

Birley, M. H. (1979). The estimation and simulation of variable developmental period, with application to the mosquito Aedes aegypti (L.). Res. Popul. Ecol. 21: 68-80

Braner, M., Hairston, N. G. (1989). From cohort data to life table parameters via stochastic modeling. In: McDonald, L. L., Manly, B. F. J., Lockwood, J. A., Logan, J. A. (eds.) Estimation and analysis of insect populations. SpringerVerlag, Berlin, p. 81-92

Brooks, J. L., Dodson, S. I. (1965). Predation, body size and composition of the plankton. Science 150: 28-35

Carlotti, F. (1990). Modèle de recrutement d'espèces marines: Couplage du bilan de matière individuel et de la dynamique de population. Ph.D. thesis, Université Paris 6

Carlotti, F., Sciandra, A. (1989). Population dynamics model of Euterpina acutifrons (Copepoda: Harpacticoida) coupling individual growth and larval development. Mar. Ecol. Prog. Ser. 56: 225-242

Confer, J. L., Cooley, J. M. (1977). Copepod instar survival and predation by zooplankton. J. Fish. Res. Bd Can. 34: 703-706

Cowgill, U. M., Williams, D. M., Esquivel, J. B. (1984). Effects of maternal nutrition on fat content and longevity of neonates of Daphnia magna. J. Crustacean Biol. 4: $173-190$

Dawirs, R. R. (1984). Influence of starvation on larval development of Carcinus maenas L. (Decapoda: Portunidae). J. exp. Mar. Biol. Ecol. 80: 47-66

Derenbach, J. B., Astheimer, H., Hansen, H. P., Leach, H. (1979). Vertical microscale distribution of phytoplankton in relation to the thermocline. Mar. Ecol. Prog. Ser. 1: $187-193$

Durbin, A. G., Durbin, E. G. (1981). Standing stock and estimated production rates of phytoplankton and zooplankton in Narragansett Bay, Rhode Island. Estuaries 4: 24-41

Fager, E. W. (1973). Estimation of mortality coefficients from field samples of zooplankton. Limnol. Oceanogr. 18: 297-301

Frogner, K. J. (1980). Variable developmental period: intraspecific competition models with conditional age-specific maturity and mortality schedules. Ecology 61: 1099-1106

Gehrs, C. W., Robertson, A. (1977). Use of life tables in analyzing the dynamics of copepod populations. Ecology 56: 665-672

Greene, C. H. (1986). Patterns of prey selection: implications for predator foraging tactics. Am. Nat. 128: 824-839

Greene, C. H. (1988). Foraging tactics and prey-selec- 
tion patterns of omnivorous and carnivorous copepods. Hydrobiologia 167/168: 295-302

Hairston, N. G. Jr, Braner, M., Twombly, S. (1987). Perspective on prospective methods for obtaining life-table data. Limnol. Oceanogr. 32: 517-520

Hastings, A. (1983). Age-dependent predation is not a simple process. I. Continuous time models. Theor. Popul. Biol. 23: $347-362$

Hunter, J. R. (1981). Feeding ecology and predation of marine fish larvae. In: Lasker, R. L. (ed.) Marine fish larvae: morphology, ecology, and relation to fisheries. Washington Sea Grant Program, Seattle, p. 33-79

Huntley, M. E., Ciminiello, P., Lopez, M. D. G. (1987). Importance of food quality in determining development and survival of Calanus pacificus (Copepoda: Calanoida). Mar. Biol. 95: 103-113

Jones, R. (1958). Lee's phenomenon of apparent change in growth-rate' with particular reference to haddock and plaice. Int. Comm. Northwest Atlantic Fish., Spec. Publ. No. 1: 229-251

Jones, R. Henderson, E. W. (1988). Simulation studies of fish larval survival. In: Rothschild, B. J. (ed.) Toward a theory on biological-physical interactions in the world ocean. Kluwer Academic Publishers, Dordrecht, p. 343-372

Kawabata, K. (1989). Natural development time of Eodiaptomus japonicus (Copepoda: Calanoida) in Lake Biwa. J. Plankton Res, 11: 1261-1272

Kimmerer, W J. (1983). Direct measurement of the production: biomass ratio of the subtropical calanoid copepod, Acrocalanus inermis. J. Plankton Res. 5: 1-14

Kimmerer, W. J., McKinnon, A. D. (1987). Growth, mortality, and secondary production of the copepod Acartia tranteri in Westernport Bay. Australia. Limnol. Oceanogr 32 $14-28$

Klein Breteler, W. C. M., Franz, H. G., Gonzalez, S. R. (1982). Growth and development of four calanoid copepod species under experimental conditions. Neth. J. Sea Res. 16: 195-207

Landry, M. R. (1978). Population dynamics and production of a planktonic marine copepod, Acartia clausi, in a small temperate lagoon on San Juan Island, Washington. Int. Rev. ges. Hydrobial. 63: 77-119

Landry, M. R. (1983). The development of marine calanoid copepods with comment on the isochronal rule. Limnol. Oceanogr 28: 614-624

Lee, R. M. (1912). An investigation into the methods of growth determination in fishes. Cons. perm. int. Explor. Mer, Publ. Circonstance $63.35 \mathrm{p}$

Loeblich, III, A. R. (1975). A seawater meduum for dinoflagellates and the nutrition of Cachonina niei. J. Phycol. 11 $80-86$

Lonsdale, D. J. (1981). Influence of age-specific mortality on the life history traits of two estuarine copepods. Mar. Ecol. Prog. Ser. 5: 333-340

Lonsdale, D. J., Heinle, D. R., Siegfried, C. (1979). Carnivorous feeding behavior of the adult calanoid copepod Acartia tonsa Dana. J. exp. mar Biol. Ecol. 36: 235-248

Lund, J. W. Kipling, C., LeCran, E. D. (1958). The inverted microscope method of estimating aigal numbers and the statistical basis of estimations by counting. Hydrobiologia 11: $143-170$

Marcus, N. H. (1985). Population dynamics of marine copepods: the importance of genetic variation. Bull. mar. Sci. 37: $684-690$

McLaren, I. A. (1976a). Inheritance of demographic and production parameters in the marine copepod Eurytemora herdmani. Biol. Bull. mar biol. Lab., Woods Hole 151. 200-213

McLaren, I. A. (1976b). Ecological and genetical strategies in Pseudocalanus production. Comm. Meet. int. Coun. Explor. Sea C.M.-ICES/L: 5, 8 p.

McLaren, I. A. (1978). Generation lengths of some temperate marine copepods: estimation, prediction, and implications. J. Fish. Res. Bd Can. 35: 1330-1342

McLaren, I. A., Corkett, C. J. (1978). Unusual genetic variation in body size, development times, oil storage and survivorship in the marine copepod Pseudocalanus. Biol. Bull. mar biol. Lab., Woods Hole 155: 347-359

Metz, J. A. J., de Roos, A. M., van den Bosch, F. (1988) Population models incorporating physiological structure: a quick survey of the basic concepts and an application to size-structured population dynamics in waterfleas. In: Ebenman, B., Persson, L. (eds.) Size-structured populations. Springer-Verlag, Berlin, p. 106-126

Miller, C. B., Huntley, M. E., Brooks, E. R. (1984). Postcollection molting rates of planktonic marine copepods: measurement, applications, problems. Limnol. Oceanogr. 29: $1274-1289$

Mullin, M. M., Brooks, E. R. (1967). Laboratory culture, growth rate, and feeding behavior of a planktonic marine copepod. Limnol. Oceanogr. 9: 138-142

Mullin, M. M., Brooks, E. R. (1970). The ecology of the plankton oft La Jolla, California, in the period April through September, 1967. VII. Production of the planktonic copepod, Calanus helgolandicus. Bull. Scripps Inst. Oceanogr 17: 89-103

Mullin, M. M., Brooks, E. R., Reid, F. M. H., Napp, J., Stewart, E. F. (1985). Vertical structure of nearshore plankton off Southern California: a storm and a larval fish food web. Fish. Bull. U.S. 83: 151-170

Myers, R. A., Runge, J. A. (1983). Predictions of seasonal natural mortality rates in a copepod population using lifehistory theory. Mar. Ecol. Prog. Ser. 11: 189-194

Nisbet, R. M., Gurney, W. S. C. (1983). The systematic formulation of population models for insects with dynamically varying instar duration. Theor. Popul. Biol. 23: 114-135

Ohman, M. D. (1986). Predator-limited population growth of the copepod Pseudocalanus sp. J. Plankton Res. 8: 673-713

Omori, M., Ikeda, T (1984). Methods in marine zooplankton ecology. John Wiley \& Sons, Inc., Toronto

Owen, R. W. (1989). Microscale and finescale variations of small plankton in coastal and pelagic environments. $J$. mar Res. 47: 197-240

Paffenhöfer, G.-A. (1970). Cultivation of Calanus helgolandicus under controlled conditions. Helgoländer wiss. Meeresunters. 20: 346-359

Peterson, W T (1986). Development, growth and survivorship of the copepod Calanus marshallae in the laboratory. Mar Ecol. Prog. Ser. 29: 61-72

Peterson, W T., Painting, S. J. (1990). Developmental rates of the copepods Calanus australis and Calanoides carinatus in the laboratory, with discussion of methods used for calculation of development time. J. Plankton Res. 12: 283-293

Rigler, F. H., Cooley, J. M. (1974). The use of field data to derive population statistics of multivoltine copepods. Limnol. Oceanogr 19: 636-655

Saunders, J F., III, Lewis, W. M. Jr (1987). A perspective on the use of cohort analysis to obtain demographic data for copepods. Limnol. Oceanogr. 32: 511-513

Sciandra, A. (1986). Study and modelling of development of Euterpina acutifrons (Copepoda, Harpacticoida). J. Plankton Res. 8: 1149-1162 
Skinner, D. M., Graham, D. E., Holland, C. A., Mykles, D. L., Soumoff, C., Yamaoka, L. H. (1985). Control of molting in Crustacea. Crustacean Issues 3: 3-14

Sokal, R. R., Rohlf, F. J. (1981). Biometry. W. H. Freeman \& Co., San Francisco

Tessier, A. J., Henry, L. L., Goulden, C. L. (1983). Starvation in Daphnia: energy reserves and reproductive allocation. Limnol. Oceanogr 28: 667-676

Thompson, B. M. (1982). Growth and development of Pseudocalanus elongatus and Calanus sp. in the laboratory. J. mar biol. Ass. U.K. 62: 359-372

Uye, S. (1982). Population dynamics and production of Acartia clausi Giesbrecht (Copepoda: Calanoida) in inlet waters. J. exp. mar. Biol. Ecol. 57: 55-83

Vidal, J. (1980a). Physioecology of zooplankton. I. Effects of phytoplankton concentration, temperature, and body size

This article was presented by N. D. Holland, La Jolla, California, USA on the growth rate of Calanus pacificus and Pseudocalanus sp. Mar. Biol. 56: 111-134

Vidal, J. (1980b). Physioecology of zooplankton. II. Effects of phytoplankton concentration, temperature, and body size on the development and molting rates of Calanus pacificus and Pseudocalanus sp. Mar Biol. 56: 135-146

Weglenska, T (1971). The influence of various concentrations of natural food on the development, fecundity and production of planktonic crustacean filtrators. Ekol. Pol. 19: $427-473$

Wilkinson, L. (1989). SYSTAT: the system for statistics. Systat, Inc., Evanston, Illinois

Zaret, T. M. (1972). Predators, invisible prey, and the nature of polymorphism in the Cladocera (class Crustacea). Limnol. Oceanogr 17: 171-184

Manuscript first received: November 1, 1990

Revised version accepted: April 24, 1991 